\title{
Perspective
}

PERSPECTIVE Actualité en histoire de l'art

Comptes rendus | 2010

\section{Ségolène Le Men, Monet, Paris, Citadelles \& Mazenod, 2010}

Chantal Georgel

\section{(2) OpenEdition}

Journals

Édition électronique

URL : http://journals.openedition.org/perspective/2652

DOI : $10.4000 /$ perspective. 2652

ISSN : 2269-7721

Éditeur

Institut national d'histoire de l'art

Référence électronique

Chantal Georgel, « Ségolène Le Men, Monet, Paris, Citadelles \& Mazenod, 2010 », Perspective [En ligne], Comptes rendus, mis en ligne le 08 août 2013, consulté le 01 octobre 2020. URL : http://

journals.openedition.org/perspective/2652; DOI : https://doi.org/10.4000/perspective.2652

Ce document a été généré automatiquement le 1 octobre 2020. 


\section{Ségolène Le Men, Monet, Paris, Citadelles \& Mazenod, 2010}

\section{Chantal Georgel}

\section{RÉFÉRENCE}

Ségolène Le Men, Monet, Paris, Citadelles \& Mazenod, 2010. 
1 Comment apprécier la complexité de l'impressionnisme à sa juste valeur? Telle est la question posée autour de l'Impressionnisme aujourd'hui.

2 Certainement en lisant le livre que Ségolène Le Men consacre à Monet. Cette question parcourt en effet le texte, en parallèle à celle que pose explicitement l'auteur : comment dire sans redire, tant il est vrai que l'on a trop souvent l'impression que "tout a été dit " sur de tels artistes? À ces questions, Le Men apporte une multitude de réponses, en interrogeant la vie et l'œuvre de Monet au plus près de ses réalités, en les soumettant

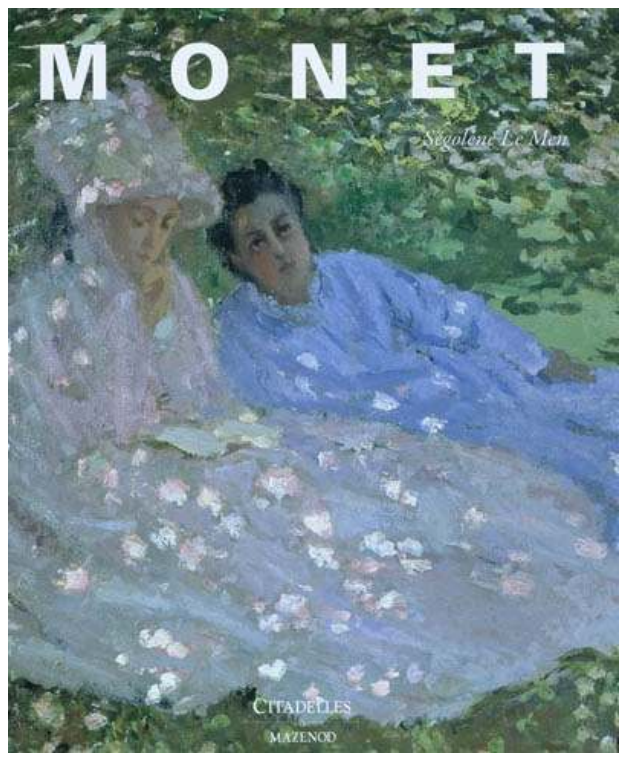
constamment à un feu croisé d'analyses faisant appel à toute une panoplie de disciplines et de sources (histoire de l'art certes mais aussi histoire, musique, littérature...), et en mettant en œuvre les nombreuses compétences que lui offre sa formation et sa longue expérience de l'interdisciplinarité. Rien de plus instructif - et passionnant - que les aperçus que ce travail nous offre sur des domaines souvent peu ou mal exploités : la caricature, le dessin d'amateur, la pratique du paysagiste, le sens des formats, les rapports de l'artiste avec les marchands, ses stratégies d'exposition et de reconnaissance... L'auteur examine la naissance du regard de l'artiste, la manière dont il a été nourri, au contact d'une société d'images, d'arts tant "savants " que populaires, ainsi que dans la rencontre avec ces hommes, artistes, critiques ou marchands, que l'on peut suivre à travers une lecture attentive de son importante correspondance. Si tout ce travail - exemplaire - se concentre autour d'une personnalité, il dit bien plus que cela. Il constitue un socle de réflexion sur lequel peut s'appuyer toute étude sur l'impressionnisme et, au-delà, sur l'art du paysage, sa réussite tenant pour beaucoup à ce qu'il est, à l'image de l'impressionnisme, constitué de multiples touches, très fines et pleines de lumières, se fondant dans une problématique large et un tableau propre à satisfaire pleinement les sens et l'intelligence du lecteur. 